\title{
Miners' Tacit Knowledge: A Unique Resource for Developing Human-oriented Lean Mining Culture in Deep Mines
}

\author{
M. A. Sanda ${ }^{1}$, J. Johansson $^{1}$, B. Johansson ${ }^{1}$ \\ ${ }^{1}$ Centre of Advanced Mining and Metallurgy (CAMM), Division of Human Work Sciences, Department of Business \\ Administration, Technology and Social Sciences, Luleå University of Technology, Sweden. \\ Email: mohami@1tu.se, jan.johansson@1tu.se, bo.johansson@1tu.se
}

\begin{abstract}
This research explored the significance of retaining aspects of traditional mining culture attributes as value-adding waste in the introduction of lean mining. The purpose was to understand the influences that aspects of human practices derived from miners' tacit knowledge, and reinforced by traditional mining culture, could have in the molding of a lean culture to facilitate the introduction and sustenance of the lean mining philosophy. Historical and actual data were collected and analyzed by viewing mine culture as attributes, such as values, beliefs, schemas, and implicit theories commonly held among the mine workforce. It is concluded that since the knowledge-oriented humanadded value held by individual miners is most commonly transferred through personal experience, such knowledge could be extracted to enhance the development of a humanoriented leaner mining culture to encapsulate the existing lean mining philosophy.
\end{abstract}

Keywords - Traditional mining, lean mining, mining culture, human-added value, underground mines.

\section{INTRODUCTION}

Firms in different industries are increasingly pursuing the lean philosophy in bids to enhance their production efficiency. Firms in the mine industry are not an exception. There are many mining firms that are characteristically global with concessions in different countries. These firms are mostly ethnocentric-oriented and adapt their operations to suit a country's specific work environments in order to enhance their production and performance stabilities.

The growing competition in the mining industry has created the need for many mining firms to simultaneously increase productivity and cut down cost. In meeting this need, most mining firms have found it necessary to introduce the lean mining philosophy in their operations in order to streamline values-based activities in their production systems. By this philosophy, the mine firms hope to eliminate waste (e.g. time) in their production process, and by implication, cut down costs.

Two priority tasks for leaner mining have been proposed by [1]. The first task is to improve the reliability of mining equipment. The second task is to create a continuous mining process for hard rock mining. These two lean tasks focus on removing sources of disturbances that could prevent the creation of a continuous mining production process. The conduction of these lean tasks will require the development of the appropriate mining culture to enhance their sustenance towards successful implementation. As such, most mining firms had to contend with diverse sets of employees with self-oriented and well-defined views on the mining work environment, which has been bounded in time as mining cultural attributions perceived and held by miners as important guides for enhancing work life and productivity in the mines. By viewing mining culture as a function of the human and technology-oriented tasks and routines defined by the firm's structured programs, and also as a composite function of attitudes and beliefs held by mine workers, its significance in the introduction of the lean mining concept needs to be understood. This is because culture, as an entity, is shared among members of organizations, but yet still, not every individual will perceive, think, and feel culture attributions in exactly the same way.

The purpose of this study therefore, was to understand whether employee behavioral attribution to old mining culture have relevance in the development of a lean mining culture. In other words, this paper sought to understand whether mine workers will strive to avoid uncertainty by relying on social norms, rituals, and practices derived from old mining culture when a mine introduces the lean concept in its operations. This exploration is motivated by the realization that many firms that have learnt and applied powerful lean tools have had their efforts constrained, because the lean culture required to sustain the tools was missing. Since mining culture could be manifested in several ways, it is viewed in this study as a signification of attributes such as values, beliefs, schemas, and implicit theories commonly and collectively held by mine workers.

\section{LITERATURE REVIEW}

\section{Lean Production}

Lean production is a production practice that considers the expenditure of resources for any goal other than the creation of value for the end customer to be wasteful, and thus a target for elimination. Working from the perspective of the customer who consumes a product or service, "value" is defined as any action or process that a customer would be willing to pay for. Basically, lean is centered on preserving value with less work. The lean concept highlights the prevailing variation on the theme of 
efficiency related to the optimization of production flow. It also perceived as a signification of the recurring theme in both human and organizational work highlighting the significance of increased efficiency, and decreased waste in the value chain of the production activity system. This based on the argument that the activity system of the production value chain consists of bounded set of interdependent behaviours whose characteristics, using Aldrich's [2] prescription, could be viewed as influenced by the type of technology. As such, the lean philosophy represent a more refined version of the earlier efficiency efforts by building upon classical organizational concepts such as Taylorism and Fordism, and learning from their mistakes.

\section{Lean Mining Philosophy}

Due to the constantly increasing scale for firms in the mining industry to produce more, most of them have found it necessary to engage in mass production processes, but which process also brought in its wake increased cost of production along the value chain. The bid to negotiate such production cost increase has led most firms in the mine industry to introduce the lean mining concept in their value chain in order to facilitate the realignment of their production processes towards improved productivity. It has been argued by [3] that improved productivity leads to leaner operations which help in exposing waste and quality problems in the production value chain.

Waste in the production system has been categorized by [4] into three distinct types; (i) the non-value adding type, which is pure waste involving unnecessary actions that need to be completely eliminated, (ii) the valueadding waste which is associated with the conversion or processing of raw materials or semi-finished products through the use of manual labour, and (iii) the necessary, but non-value adding waste which result from operations that may be wasteful, but yet necessary under the prevailing operating procedures, and whose elimination requires major changes to the operating system that may not be immediately possible.

In a study on making a mine leaner, [1] assessed the potential transfer of the 14 Toyota Production System principles into lean mining. Using the learning they derived from the reviews, together with experiences gained from the introduction of lean mining in an underground mine in Sweden, [1] proposed two priority tasks for making a mine leaner. Firstly, the reliability of mobile mining equipment must be significantly improved by redesigning them and also improving their operating and maintenance procedures. In the opinion of [1], this task constitutes the single most important step towards a lean mining operation, because it would enhance the elimination of pure, non-value adding waste to emanate from unnecessary actions along the production value chain. Secondly, a continuous mining process must be created for hard rock mining. This task requires the development of machinery that can break rock and load it to a conveyor system or to a waiting truck, and at the same time install the required rock support behind and above itself [1]. With such machinery, whether they are valueadding waste and/or the necessary, but non-value waste in the mining operations could be removed. These obstacles might be associated with the use of manual labour used to compliment production activities. They might also be associated with operations considered wasteful, but necessary in the prevailing operating procedures, since their elimination might necessitate the complete overhaul of the production system. The issue of interest here concerns the issue of whether these two tasks for introducing lean mining could be carried out without them being constrained by the mining culture.

\section{Mining Culture}

Culture and leadership are probably the most written about and the least understood topics in the social sciences. This is not only because social scientists find these two topics very challenging, but also because these two seem necessary for satisfying human existence [5]. It has been argued by [5] there is no universally agreed upon definition of culture among social scientists. Social scientists generally use the term to refer to a set of parameters of collectiveness that differentiate the collectiveness from each other in meaningful ways. The focus is on the "sharedness" of cultural indicators among members of the collectivity.

The specific criteria used to differentiate cultures usually depend on the preferences of the investigator and the issues under investigation, and tend to reflect the discipline of the investigator [5]. Culture has been defined by [6] as the shared motives, values, beliefs, identities, and interpretations or meanings of significant events that result from common experiences of members of a collective, and which are transmitted across age generations. Since the outlined attributes in this definition are psychological attributes, then this definition can be applied at both the societal and organizational levels of analysis [5]. Projecting this to the mining environment, mining culture can be manifested in two distinct ways. The first is to view the mine culture as attributes, such as values, beliefs, schemas, and implicit theories commonly by the miners. The second is to view the mine culture as the long-term functioning practices that have become entrenched in the work environment and translated into inherent practices in the mine's work organization.

The mining culture can thus be described as a composite function of attitudes and beliefs held by the mine's workers. Thus for most miners, the manner in which they carry and present themselves within the work environment is very important. The way of carrying oneself is often perceived as a reflection of ones personality. By implication, the portrayal of a certain attitudinal and personality qualities, such as confidence, independence and motivation, are perceived as prerequisite to the enjoyment of a successful career in the deep mining industry. The projected reality in this regard 
is that mine workers need not only the skills and ability to work effectively, but also the commitment to the lifestyle associated with the industry. For example, [1] has observed that on a scale of 1-10, the Toyota Car manufacturing company is likely to be in the success range of around 9 in their implementation of the lean philosophy. They [1] also noted that the leanest production companies in Sweden, such as Scania, might reach a success range of 7 . They [1] rated the mining industry to have a success range level of between 3 and 4 , which is lower than that for the mineral processing plants. This success variation therefore, raises the question of whether lean mining could be attained by only improving the reliability of the mining equipment, and creating a continuous mining process in an environment where the mine culture could have entrenched influence on the workers' attitudes and behaviours towards the lean philosophy.

\section{METHODOLOGY}

\section{Data Collection}

Two categories of data (i.e., historical and actual data) were collected. The historical data was collected from reports detailing the historical transitions of underground mining from traditional human-oriented mining to modern technology-oriented mining. The actual data was collected from an underground mine in Northern Sweden.

The mine uses cut-and-fill and sub-level stoping as the basic methods in its underground mining. In applications of the cut-and-fill method, the void left by the mined ore is filled with tailings from the concentrator or with natural sand. Sub-level stoping is a large scale method. The ore is mined using 10-20 meter-long vertical drill holes and the void after mining is filled with waste rock. Actual mining operations consist of drilling, charging, blasting, scaling and mucking. In addition to miners, other personnel include maintenance crew, machine fitters, electricians and transport and storage personnel. Transport between different levels and the mine stopes is via a ramp, an irregularly twisting path. The ramp can be used for rapid transport of machines, materials and personnel between different stopes on the same level, and between different levels and the surface.

The sources of data were the mines' employees. Data was collected through recorded interviews, and also through video recordings and on-site observations. In the data collection procedure, four separate visits (shifts) were made to the mine work environment located 1.3 kilometers underground in the company of four different mineworkers engaged in rock drilling as well as roof bolting activities using the automated drilling and bolting machines. Each visit lasted seven hours which is the work duration for each shift.
The recorded interviews were transcribed and scripted [7]. The validity of the scripts generated for all the interviewees was established after crossing-checking with each interviewee. Interpretive descriptive analysis was conducted to understand the transition in the mines work culture from traditional mining to lean mining. This was because in the dialogue (i.e. interview conversation), the subjects (interviewees) did not only answer the questions prepared by the researcher (interviewer), but they (interviewees) were also given the space to formulate their own conceptions of their lived world. The expectation here was that the sensitivity of the interview approach and its closeness to the interviewees" "lived world" would lead to the evolution of knowledge that could be used to understand the relative outcome of the commercialisation processes of the organization studied. An interpretive description qualitative approach ([8], [9], [10], [11]) was used to analyze the scripts generated from the interviews.

According to [8], it can become almost impossible for a researcher to untangle the shared component of a subjective experience from the narratives that people place them in, and so qualitative research tends to require thoughtful analysis of the relationship between the data sources and the findings derived from them. With this observation in mind, the experiences of the interviewees, alongside the historical information relative to changes in the mines' cultural attributions (i.e. from traditional mining to lean mining) were analyzed.

\section{RESULTS AND DISCUSSION}

\section{Transiting From Traditional Mining to Lean Mining}

The historical data showed that the introduction of high technology in underground mines has resulted in new forms of workplace learning with fewer spaces for old types of competencies, attitudes and ideals. In this regard, old style of macho behaviour was directly challenged by a new type of worker identity, knowledge, skill and masculinity underlined by a new workplace culture. A reflection of the transformation from direct mining underground to the use of remote control at the surface captured over a period fifty years at Kiruna iron ore mine in Sweden by [12] is shown in figure 1 below. In this new workplace culture, the miner is moved away from directly facing and interacting with the rock being mined underground, and relocated to a new work station on the earth surface from where she/he carries out tasks underground with the combined aid of technology and abstract knowledge. In this new work environment which [12] labeled as 'the sky', the miner is able to read and understand projected data either in the form of pictures and/or symbols, and which data she/he relate to different measurement test results. 


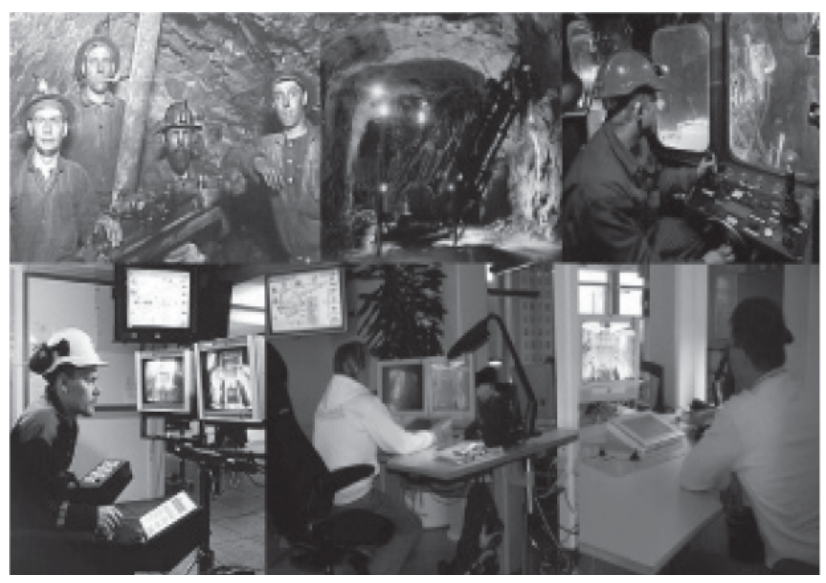

Fig. 1. Miners' work transformation from underground to the surface at Kiruna mine [12].

There was the transformation of miners skills from the traditional craftsman-like qualifications reflected in a degree of autonomy, the use of manual skills and sensitivity to material ('rock-sense') to the more technical qualifications based on abstract knowledge necessary to operate the new advanced technologies that became central to the production processes. The workers were faced with new demands for teamwork, responsibility, and autonomy, as well as a comprehensive understanding of production flow. Additionally, tasks reflecting the mine workers' tacit knowledge were formalized and codified into automated routines and computer programs. This signified contradictory movements of upskilling (rapidly changing skill demands, more theoretical and comprehensive tasks) and deskilling (fragmentation of individual craft knowledge and whole tasks) [13].

The resilience of the traditional workplace culture was demonstrated when the operation of the front loaders was moved from underground to seventh floor of the office building. The workers still saw themselves as underground miners, and reinforced this by changing their clothes after every shift in spite of the fact that they were just as clean as when they commenced their shift. They wanted themselves to be seen as miners [13].

The introduction of remote control, and especially the move up to seventh floor was met with miners segregating themselves into groups of 'us' and 'them'. The underground miners, especially those doing manual work tasks, perceived themselves as 'the real miners' in comparison to their colleagues who use technological tools and whom they viewed as weak and somewhat feminine entities. In the minds of most miners, the traditional approach continued to be the symbol of mining work. One example of this was the miners sometimes bragging about their own contribution to the increased production and the company's great profit, the new technology being seen as a threat to the 'uniqueness' of mining work. Though these attitudes became less predominated, they unconsciously continued to be part of the mine worker's identity, workplace culture and workplace learning [13].
Functionality of Miners in Lean Mining Environment

Analysis of the interview data showed that the introduction of high technology to add economy to workflow in the mine resulted in new forms of workplace learning with fewer spaces for old types of competencies, attitudes and ideals. The portrayal of certain attitudinal and personality qualities among the miners, such as confidence, independence and motivation, was found to serve as prerequisite to the enjoyment of a successful work life. The relevance of this attitudinal and personality portrayal was found to be tied to the continued belief of the mine workers that working in a deep mine is a dangerous affair which has to be approached slowly and cautiously, irrespective of the technological advances made in the design of work stations and tools. This belief ingrained itself in the consciousness of the mine workers, who also used it to justify their continued reverence in the following old mining cultural belief.

As a miner, it must take a couple of years before "you can see the rock" and "feel the rock".

Everyday when I come to work, I am always cautious that anything can happen. I do not come and enter here, just relax and finish and go

home. I have to be in this kind of state every working day. I have to be sharp.

The expression above portrays a sense of macho behaviour underlined by traditional mining culture, but which behaviour is directly challenged by a new type of worker identity and masculinity underlined by a new workplace culture. In this new workplace culture, the miner is moved away from directly facing and interacting with the rock being mined underground, and relocated to a new work station on the earth surface from where she/he carries out mining tasks underground with the combined aid of technology and abstract knowledge. In this new work environment, the miner is able to read and understand data transmitted from underground to the screen of his/her control monitor.

The results obtained also indicated that even in the situation where the mine worker is not relocated to "the Sky", she/he remains underground, but work in the comfort of high technology machines with robotic features (see figure 2 below) that interact directly with the rocks being mined. Yet, despite the production advantages introduced by these technological changes, the shift it introduced to the work culture also generated a semblance of challenges. The data showed that the old mining culture is still an important feature of workplace learning in the underground mine, in that it informs the way the miners learn and construct knowledge and skills. For example, it was found that the operators of a high technology machine engaged in a roof drilling and bolting operations in the deep mine used techniques enhanced by old mining culture to negotiate and accelerate the tasks. In this activity, the miner's action is supposed to be technologically-guided via a sequential computer program which requires that a hole is drilled in the rock first and then cement pumped (i.e. grouted) in the drilled hole. 


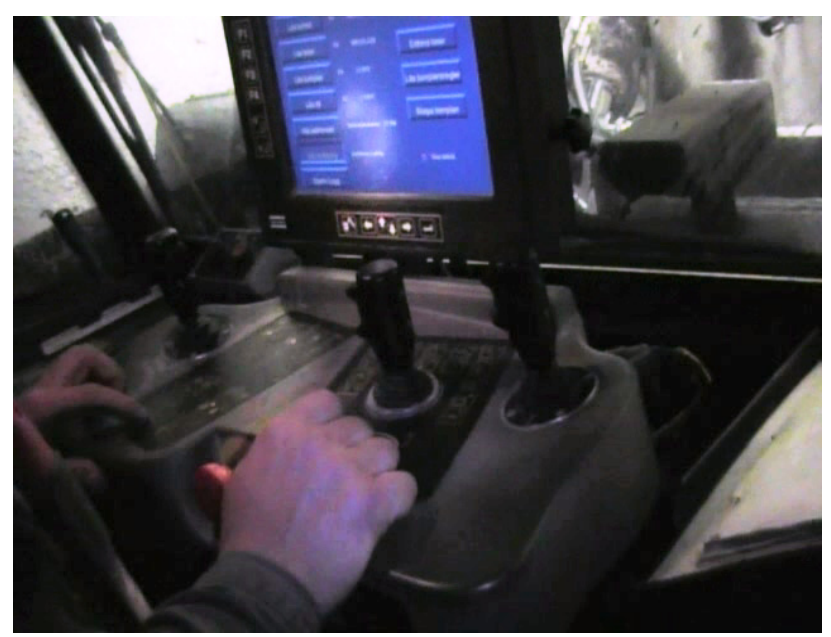

Fig. 2. Miner operating a high technology rock drilling machine from underground

A bolted rod is then inserted in the cement-filled hole to complete the task. In negotiating this task, the operator would drill as many holes in the rock as possible first. Afterwards, cement is pumped in each drilled hole followed immediately by the insertion of bolted rods. Technologically, this task negotiation is perceived impossible with a fully mechanized bolting jumbo due to technical problems with positioning, and the possibility of rock strength being poor with rock fragments caving into the just drilled boreholes. Yet, the ability of the miners to carry out this task negotiation could be related to skills acquired from the traditional mining process of systemic bolting introduced in the 1960s in which the grouting of cement and insertion of bolts was done manually as normal procedure.

The miners' self-developed task negotiation was found to be expressive of their skills and abilities to 'read the rock', and which expression, as reflected below, signifies their deep tacit knowledge about the rock.

I always use the experience I have acquired over the years to guide this new technologies for optimum performance. I do not write down these experiences, but I sometimes share them with some of my colleagues and the people I train over here. I explain things to them and hope that they pick it up gradually.

The expression above signifies the importance of the way most miners continued to be influenced by the old mining culture within the technology-oriented work environment. Despite the miners' use of highly reliable mobile mining equipment with improved operating and maintenance procedures which was viewed by [1] as constituting the single most important step towards a lean mining operation, the relevance of the miners deep knowledge about the rock (i.e. their skills and ability to 'read the rock') molded by the old mining culture comes into play as a result of process interruption when a hard rock is encountered. The development of the tacit knowledge was to cater for the miners' observations that the technologies they use in their task undertakings do not always get it right. The miners were of the view that even in deep mines where robotic loaders, controlled by remote technology from safe distances are used for loading task, the guide cameras used to manipulate the robots' movements do not guide the loading operations in the same efficient way as the eyes of the operator when on site. Thus by using their acquired experiences, the miners mostly find ways to guide the technology for optimum performance, but which knowledge, as the expression below indicates, remained tacit.

The suppliers of our high tech machines normally visit the mine when the company wants to buy a new machine. When they come, they do no ask us about the machines because we all see things in different ways, and there is no way to satisfy everybody. I think it will be nice if these suppliers bring their young engineers and designers to understudy us, so that they could see what their machines can do and cannot do, and also what we the miners do to enhance the functions of the machines

The miners' use of this tacit knowledge to successfully negotiate task involving hard rock, and as a consequence increase the pace of their work activities represent a "Human Added Value" useful to the creation of a human-oriented lean mining culture. The capture and modeling of this Human Added Value as a culture attribute of lean mining is important because organizations are social structures entailing sociocultural constraints that could hinder the prospects of employees playing a decisive role in improving its performance [14].

Employees' knowledge of their work environments, as well as the way they interact and commit themselves to organizational goals are thus, important elements that impact organizational culture and which mining firms need to understand ([14] [15]). The mining culture can, therefore, be described as a composite function of the attitudes and beliefs held by the mine's workers which were acquired as a result of their long-term interaction with their work context. Therefore, for most miners, the manner in which they carry and present themselves within the work environment is very important. The way of carrying oneself is often perceived as a reflection of ones personality. By implication, the portrayal of a certain attitudinal and personality qualities, such as confidence, independence and motivation, are perceived as prerequisite to the enjoyment of a successful career in the industry. This observation indicates the benefit that could be derived from mine workers by involving them in the workplace's transformation towards leaner mining. This involvement will provide them a good platform to share their tacit and explicit knowledge of the rock.

The mine workers' awareness of their tacit knowledge and their abilities to use such knowledge to enhance the tasks they are engaged in represent a critical element of their identities [17]. Drawing from the views of [18], this critical element (i.e. the human added value), together with the more formal structural aspects of the workplace, the identity aspect of work, and the symbolic 
aspects of work, and their relationships could form organizational processes and culture for optimizing lean mining operations.

\section{CONCLUSION}

This study has shown that miners' knowledge of the rock, developed as a key component of the old mining culture, and which they used to learn to cope with the problems of overcoming hard rock drilling in lean mining task represent a significant human added value to the lean mining philosophy. This is because the incorporation of this human added value enabled the lean tasks to work well enough for the entire roof-bolting activity to be considered valid, and, therefore, to be taught to new members as the correct way to perceive, think and feel in relation to those problems in lean mining. The mine workers may feel empowered when their opinions are sought and also given the opportunities to identify and explain best practices derived from old mining culture that could be molded into the lean mining philosophy.

It is therefore concluded that since the knowledgederived human-added value held by individual miners is most commonly transferred through personal experience, such knowledge could be extracted and added to the two priority tasks proposed by [1] for making a mine leaner. By implication, a human-oriented leaner mining culture to encapsulate the lean mining philosophy could be developed by giving priority to the following three issues.

- Firstly, by ensuring significant improvement in the reliability of mobile mining equipment by redesigning it and also improving its operating and maintenance procedures, in order to enhance the elimination of pure, non-value adding waste emanating from unnecessary actions along the production value chain.

- Secondly, by creating a continuous mining process for hard rock mining through the development of machinery capable of using the "shearing technique" rather than the "fragmentation by drill and blast technique" to break rock and load it to a conveyor system or to a waiting truck, and at the same time install the required rock support behind and above itself.

- Thirdly, by creating a platform to capture the miners' tacit knowledge of the rock acquired from the old mining culture and integrating such knowledge in the design and development of a lean culture to guide the work organization.

\section{REFERENCES}

[1] G. Bäckblom, E. Forssberg, S. Haugen, J. Johansson, T. Naartijärvi and B. Öhlander. Smart Mine Of The Future: Conceptual Study 2009-2010 Final Report. Sweden: MFU, 2010.

[1] H. E. Aldrich. Organizations and Environments. Stanford, California: Stanford University Press, 2008.
[2] P. Hines and N. Rich, "The seven value stream mapping tools, International Journal of Operations \& Production Management", vol. 17, no. 1, pp. 46-64, 1997.

[3] Y. Monden. Toyota Production System: An Integrated Approach to Just-in-time (3rd edn.). Norcross, Georgia: Industrial Engineering \& Management Press, 1998.

[4] J. S. Chohokar, F. C. Brodbeck and R. House, "Introduction", in Culture and Leadership across the World: The GLOBE Book of In-depth Studies of 25 Societies, J. S. Chohokar, F. C. Brodbeck and R. House, Eds. London: Lawrence Erlbaum Associates, 2007, pp. 115.

[5] J. House and M. Javidan, "Overview of GLOBE", in Culture, Leadership, and Organizations: The GLOBE Study of 62 Societies, R. J. House, P. J. Hanges, M. Javidan, P. W. Dorfman and Gupta, V. Eds. Thousand Oaks, California: Sage, 2004, pp. $9-28$.

[6] S. Kvale. Interviews: An Introduction to Qualitative Research Interviewing. Thousand Oaks, California: Sage, 1996.

[7] A. Brazier, K. Cooke and V. Moravan, "Using mixed methods for evaluating an integrative approach to cancer care: a case study", Integrative Cancer Therapies, vol. 7 , pp. 5-17, 2008.

[8] M. A. Sanda, "Impact of value-based transformational leadership in privatizing government institutions in a developing economy: A case study", Business \& Management Quarterly Review, vol. 1, no. 3, pp. 1-13, 2010.

[9] S. Thorne, S. K. Reimer and K. O'Flynn-Magee, "The analytic challenge in interpretive description", International Journal of Qualitative Methods, vol. 3, no. 1: Article 1, 2004.

[10] S. Thorne, K. S. Reimer and J. MacDonald-Emes, "Interpretive description: A noncategorical qualitative alternative for developing nursing knowledge", Research in Nursing \& Health, vol. 20, pp. 169-177, 1997.

[11] L. Abrahamsson and J. Johansson, "From grounded skills to sky qualifications: A study of workers creating and recreating qualifications, identity and gender at an underground iron ore mine in Sweden", Journal of Industrial Relations, vol. 48, no. 5, pp. 653-672, 2006.

[12] L. Abrahamsson and J. Johansson, "Future mining: Workers' skills, identity and gender when meeting changing technology", in Proc. 1st International Future Mining Conference and Exhibition, S. Sayden, Ed. Sydney, Australia: The Australian Institute of Mining and Metallurgy, 2008, pp. $213-220$.

[13] M. A. Sanda, Y. Fältholm and L. Abrahamsson, "Innovation and knowledge creation in the integration of technological, organizational and human systems", in Proc. 2010 FISCAR Conference. Helsinki, Finland, 23-25 May 2010, pp. 186-187.

[14] M. A. Sanda, Y. Fältholm, L. Abrahamsson and J. Johansson, "Using PIW as a strategic participatory tool to capture implicit knowledge in organizations", Global Journal of Strategies and Governance, vol. 2, no. 2, pp. 44$58,2011$.

[15] M. A. Sanda, Y. Fältholm, L. Abrahamsson and J. Johansson, "Problem-identification workshop as a futureoriented macroergonomic tool for managing the work environment", in Proc. of the 2010 IEEE Industrial Engineering \& Engineering Management Conference, Macau, China, 7-10 December 2010, pp. 492-496.

[16] T. Fenwick, "Learning as grounding and flying: Knowledge, skill and transformation in changing work contexts. Journal of Industrial Relations, vol. 48, no. 5, pp. 691-706, 2006

[17] J. Acker, "Gender and organizations", in Handbook of the Sociology of Gender, J. S. Chafetz, Ed. New York: Springer, 2006, pp. 177-194. 